\title{
ESSAY
}

\section{The mystery ape of Pleistocene Asia}

\author{
Fossil finds of early humans in southeast Asia may actually be the remains of an unknown ape. \\ Russell Ciochon says that many palaeoanthropologists - including himself - have been mistaken.
}

Fourteen years ago, a Nature paper by my colleagues and I described a 1.9-million-yearold human jaw fragment from Longgupo in Sichuan province, China ${ }^{1}$. The ancient date in itself was spectacular. Previous evidence had suggested that human ancestors arrived in east Asia from Africa about 1 million years ago, in the form of Homo erectus. Longgupo nearly doubled that estimate. But even more exciting - and contentious - was our claim that the jaw was related to $H$. habilis, a species of distinctly African origin. If this descendant of $H$. habilis had arrived so early into southeast Asia, then it probably gave rise to $H$. erectus in the Far East, rather than $H$. erectus itself sweeping west to east.

For many years, I used Longgupo to promote this pre-erectus origin for $H$. erectus finds in Asia. But now, in light of new evidence from across southeast Asia and after a decade of my own field research in Java, I have changed my mind. Not everyone may agree; such classifications are always open to interpretation. But I am now convinced that the Longgupo fossil and others like it do not represent a pre-erectus human, but rather one or more mystery apes indigenous to southeast Asia's Pleistocene primal forest. In contrast, $H$. erectus arrived in Asia about 1.6 million years ago, but steered clear of the forest in pursuit of grassland game. There was no pre-erectus species in southeast Asia after all.

The Longgupo site, discovered in 1984, lies 20 kilometres south of the Yangtze River in eastern Sichuan. At the beginning of the Pleistocene ( 1.8 million to 10,000 years ago) this cave sat near the northern range of a subtropical forest as rich with life as any in contemporary Africa. Unsurprisingly, the mammalian fossils dug up from Longgupo belonged to the subtropical Stegodon-Ailuropoda fauna found throughout the subtropical forested region south of China's Qinling Mountains (see map). The name comes from two common members - the extinct elephant-like Stegodon and the bear-like giant panda, Ailuropoda. It includes primates such as the extinct giant ape Gigantopithecus, as well as the ancestors of the living orangutan (Pongo) and gibbon (Hylobates).
But Longgupo also yielded a mystery jaw fragment, including the fourth premolar and the first molar. Although obviously primate, the worn enamel surfaces made precise classification difficult. Some had called it an ape whereas others saw an early human. In 1992, colleagues and I were invited to Longgupo to provide a reliable age determination and to help understand the palaeoanthropology.

The 1.8-million-2-million-year-old jaw was smaller than that of any known orangutan, living or extinct. We also compared it with primate dental fossils from the site of Lufeng, in neighbouring Yunnan province. Lufengpithecus was of the right size and general morphology, but the age was wrong: Lufeng and similar sites belonged to the late Miocene period, about 7 million-9 million years ago. Some possible stone tools found at the site seemed to support a human classification. Asian $H$. erectus was the obvious possibility, but the size, tooth proportions and root structure were not quite right. Dissatisfied with the usual regional comparisons, we looked to Longgupo's possible links with early African humans such as H. habilis, whose Great Rift Valley fossils are as old as 2.3 million years. Our Nature announcement ${ }^{1}$ thus presented the Longgupo jaw as a newcomer to the Stegodon-Ailuropoda fauna: an African hominin more primitive than $H$. erectus.

\section{Pre-erectus claims}

We weren't the first or last to suggest that a pre-erectus African hominin migrated to east Asia. In the 1940s and 1950s pre-erectus African claims were made for fossils from Sangiran, on Java, Indonesia. Early in Sangiran's long history of $H$. erectus discoveries, a couple of massive jaws seemed similar to those of South African australopiths - they were coined 'Meganthropus'. But as more fossils were discovered at Sangiran, it became clear that the Meganthropus jaws were merely a local variant of $H$. erectus.

Just this year, claims for a pre-erectus African in Asia have also surfaced to explain the evolution of Indonesia's Homo floresiensis, popularly known as the Liang Bua 'hobbit'. Discovered in 2003 , and dated to just 95,000 to 17,000 years ago, the Liang Bua skeleton is a diminutive species significantly different from all other known humans. The discoverers proposed that the diminutive $H$. floresiensis evolved from a southeast Asian H. erectus group that became isolated on Flores: faced with limited resources, the erectus group dwarfed to match the smallisland conditions. However, recent studies of Liang Bua wrist and foot bones reveal primitive anatomies reminiscent of $H$. habilis or Australopithecus, again leading some to propose a pre-erectus African origin for the species. The problem is that no comparable wrist or foot bones are known for $H$. erectus, making it impossible at this time to exclude a local variant of $H$. erectus as the ancestor of the Liang Bua 'hobbit'.

So our claim of a pre-erectus African hominin living in east Asia fell into a long line of such arguments. It was met with healthy scepticism. We were first faced with the response that Longgupo was an orangutan, but we were able to show that the two teeth lay significantly outside the orangutan range of variation ${ }^{2,3}$. Later, we had to field a serious proposal that Longgupo belonged to Lufengpithecus ${ }^{4,5}$. Although the age disparity remained troubling, the dental similarities could not be denied. I began to imagine a mystery ape as a possible solution to the problem.

Then in spring 2005, I met with Wang Wei, director of the Guangxi Natural History Museum, to examine his collection of 33 primate teeth from Mohui cave in Bubing Basin, south China. Wang's excavations produced an excellent sample of the StegodonAiluropoda fauna. Quickly I could see that 15 teeth were those of Gigantopithecus, and 10 were probably Pongo. The remaining eight specimens did not fit with any known east Asian Pleistocene primate. 


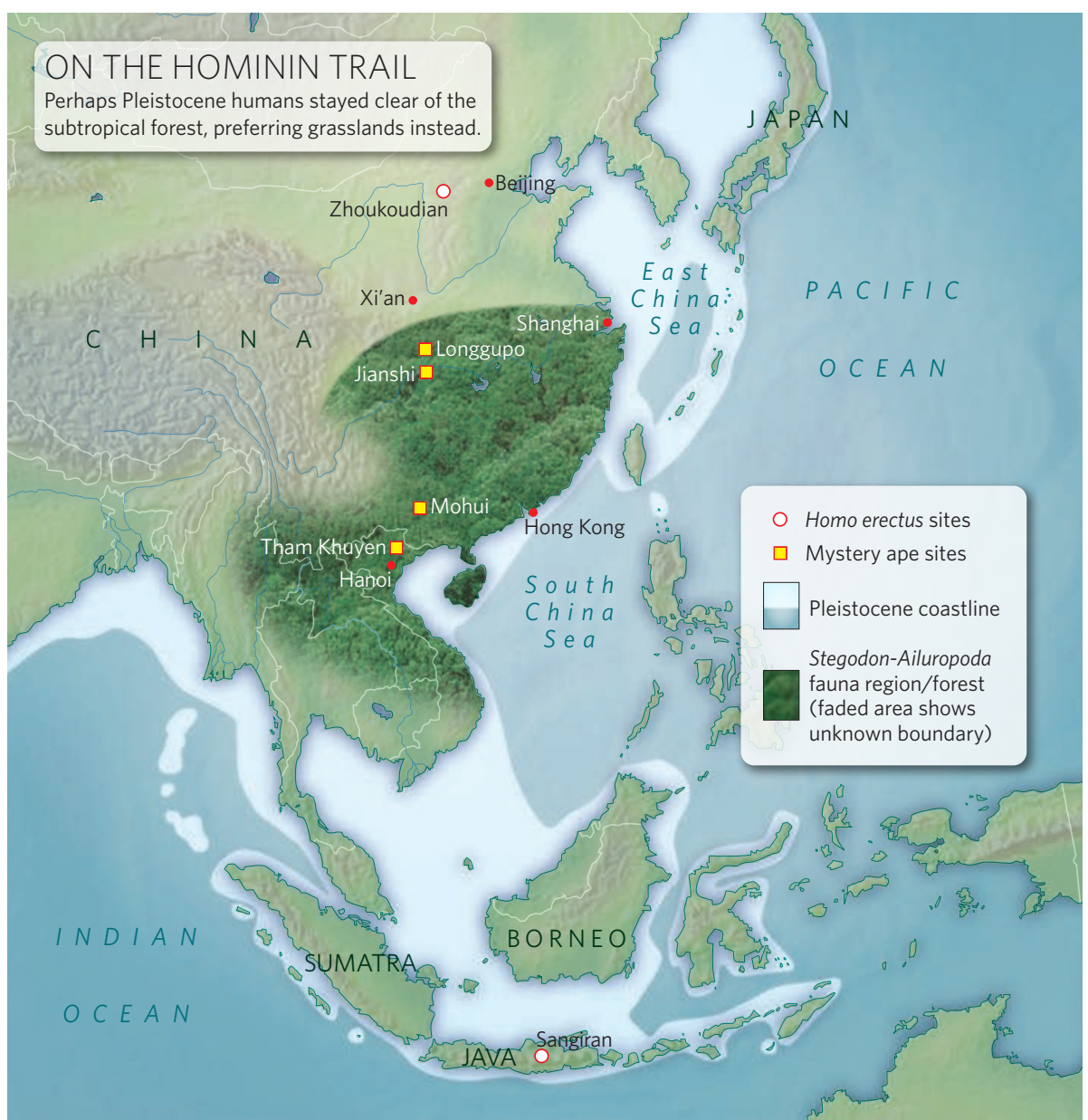

Some 15 years earlier, I had worked hard to show that Gigantopithecus had crossed paths with $H$. erectus; I wrote a book in 1990 proposing this relationship (Other Origins: The Search for the Giant Ape in Human Prehistory) and a few years later had documented evidence of the species' co-existence. In my mind the two were firmly linked. But more than a decade after the discovery, with some distance from the subject, the teeth in Wang's lab looked distinctly more ape-like than hominin.

\section{Teething problems}

Without the assumption that Gigantopithecus and $H$. erectus lived together, everything changed: if early humans were not part of the Stegodon-Ailuropoda fauna, I had to envision a chimpanzee-sized ape in its place - either a descendant of Lufengpithecus, or a previously unknown ape genus. The Mohui mystery teeth surely belonged to an unknown ape, as did Longgupo, and other human-like teeth often identified from similar cave fossils. Although I no longer consider the Longgupo jaw to be human, the two stone tools still stand as described. They must have been more recent additions to the site.
The mystery ape concept is bolstered by looking at definitive $H$. erectus finds in east Asia. Our knowledge comes mainly from two sites: Zhoukoudian near Beijing, which lies well north of the primal forest, and Sangiran in Java, which lies well south of it. Each site represents hundreds of thousands of years of $H$. erectus occupation: Sangiran beginning as early as 1.6 million years ago, Zhoukoudian beginning about 780,000 years ago ${ }^{6}$. Neither site preserves Stegodon-Ailuropoda fauna or mystery ape teeth. Homo erectus, it seems from this perspective, hunted grazing mammals on open grasslands, and did not or could not penetrate the dense subtropical forest. In fact, there is no record of early hominins living in tropical or subtropical forested environments in Africa or Asia.

In resolving the mystery, two other Asian sites come to mind: Jianshi (Hubei province, China) and Tham Khuyen (Lang Son province, Vietnam). At both sites, teeth labelled variously as Australopithecus, $H$. erectus and Meganthropus are most likely to be the mystery ape instead. Others have come to similar conclusions ${ }^{7}$; a 2009 paper identifies a tooth from Sanhe Cave (Chongzuo, Guangxi province,
China) as belonging to an unidentified ape ${ }^{8}$.

In this call to reassess historical assemblages, it is worth remembering the story of 'Hemanthropus'. Legendary fossil collector Ralph von Koenigswald created this hominin taxon in 1957, based on isolated fossil teeth found in apothecary shops across southeast Asia. Von Koenigswald viewed Hemanthropus as a distant relative of African Australopithecus. Later research revealed that these were worn or atypical orangutan teeth and Hemanthropus was quickly abandoned. But, had von Koenigswald actually discovered evidence of the mystery ape? In October 2005, I examined the original Hemanthropus collection. Among the many worn orangutan teeth I found several small ape teeth that very closely resembled the mystery ape teeth from Mohui. Perhaps von Koenigswald was the first to lay hands on the mystery ape.

The question remains: is there only one mystery ape or possibly more? It seems that there was as much diversity of apes in the southeast Asian Pleistocene as in Africa today. In modern Africa there is one large ape (the gorilla) and two smaller apes (the chimpanzee and bonobo); in Asia during the Pleistocene and recent times, we have one very large ape (Gigantopithecus), one large ape (the orangu$\tan$ ), at least one smaller ape (mystery ape) and finally a tiny ape (the gibbon).

The next step is to consider the mystery ape fossils as a group and see how they fit into the evolutionary history of the range of southeast Asian apes. Wang will head up this team effort, along with Chinese and international colleagues, including myself. Museum collections holding potential mystery-ape evidence will be examined, including those in Hanoi, Jianshi, Beijing and Frankfurt. Wang's ongoing excavations at cave sites in Guangxi’s Bubing Basin are yielding new evidence with every passing day. Possibly, there will be a chance to announce a new southeast Asian fossil ape in some future issue of this journal.

Russell L. Ciochon is chair of anthropology at the University of lowa, lowa City, lowa 52242,

USA. This Essay is based on a contribution to the book Out of Africa l: Who, When and Where? (eds, Fleagle, J. G. et al. Springer, 2009).

e-mail: russell-ciochon@uiowa.edu

1. Huang, W. et al. Nature 378, 275-278 (1995).

2. Schwartz, J. H. \& Tattersall, I. Nature 381, 201-202 (1996)

3. Huang, W. et al. Nature 381, 202 (1996).

4. Wu, X. Acta Anthropol. Sin. 19, 1-10 (2000).

5. Etler, D. A. et al. Hum. Evol. 16, 1-12 (2001).

6. Ciochon, R. L. \& Bettis, E. A. III Nature 458, 153-154 (2009).

7. Schwartz, J. H. et al. Anthropol. Pap. Amer. Mus. Nat. Hist 76, 1-24 (1995).

8. Jin, C. et al. Chinese Sci. Bull. 54, 788-797 (2009). 